\title{
Is brain plasticity preserved during aging and in Alzheimer's disease?
}

\author{
M. Mirmiran *, E.J.W. van Someren and D.F. Swaab \\ Graduate School Neurosciences Amsterdam, Netherlands Institute for Brain Research, Meibergdreef 33, 1105 AZ Amsterdam, \\ The Netherlands
}

Received 17 March 1995; revised 9 June 1995; accepted 19 June 1995

\begin{abstract}
Alzheimer's disease is a progressive neurodegenerative disorder believed to involve selective neuronal cell atrophy/loss in certain brain regions. The progress of the disease is accompanied by selective cognitive impairments and behavioral disturbances. The hypothesis has been put forward that by activation of selective brain areas throughout life one might protect or delay the degenerative process. This hypothesis, paraphrased as "a differential level of brain cell activity may account for cell selective loss" or "use it or lose it", further suggests that a certain level of neuronal plasticity persists during aging and even in Alzheimer's disease.
\end{abstract}

Keywords: Aging; Brain; Plasticity; Alzheimer's disease; Circadian rhythm; Sleep

\section{Introduction}

The interaction between the organism and its environment in shaping the brain (i.e., plasticity) has been shown by both deprivation and stimulation experiments in animals as well as human. Studies on kittens and monkeys have shown that monocular deprivation during a critical period of development induces a rewiring of the visual cortex as exemplified by the shift in binocularity of light responsive neurons [24]. Binocular vision does not develop normally in man either if only one eye is functioning during the first 5 years of life or if neither eye perceives congruent visual fields. Studies on rearing kittens in an environment in which they could only perceive either vertical or horizontal lines showed longlasting changes in cortical neurons and visual receptive fields. In other words, following such manipulations cortical neurons are preferentially responsive to either vertical or horizontal bars and not to both [7]. Social deprivation reduces learning and curiosity, increases stress reactivity and aggression and leads to inappropriate behavior and withdrawal in later social contacts. The role of both endogenously and exogenously induced neuronal activity in development and stabilization of neuronal networks has been studied extensively, e.g., blocking spontaneous activity inhibits segregation of

\footnotetext{
*Corresponding author. Fax: (31) (20) 6961 006. E-mail:
}

retinogeniculate afferents and columnar organization of the visual cortex [48].

Environmental stimulation (enrichment or complexity) has also been shown to influence brain and behavior. The germinal experiment by Hebb showed that daily training in problem solving mazes also improved the performance of the animals in other experimental tasks [18]. Rearing rats in complex environments was shown to induce: increased brain weight and cortical thickness, increased neuronal dendritic branching, an increased number of synapses per neuron, enhanced protein synthesis in the brain and a superior performance in complex mazes as compared with controls (reviewed by Rosenzweig, this volume; see also [17,31]). When assessing the effects of environmental manipulation on the brain, a distinction should be made between a subject that is passively exposed to numerous repetitive stimuli of one or more modalities and a situation in which the subject interacts actively with the environment and is involved in the selection, perception and integration of the stimuli. Held reared two kittens in total darkness, both of which were allowed for a limited time daily to explore a round cylinder painted with strips of different colors [19]. Both kittens were connected to one another and to the center of the cylinder. One kitten was allowed to move around at will and to inspect any visual field, whereas the other one was restrained to a wooden gondola and forced to watch only the visual field presented by the other. Although both kittens received a 
comparable amount of visual stimulation, the kitten which had actively observed and experienced its environment performed better than the other one on tests of visual performance in adulthood. Thus active interaction of the subject with the environment is required for plasticity to take place. This should also be considered when plasticity in Alzheimer patients is studied.

Another form of brain plasticity related to memory is the long-term potentiation in the hippocampus in which the plasticity occurs at synapse level (see for review [57]). Hebb [18] proposed a neuronal substrate for consolidated learning a type of synaptic plasticity that is called 'Hebb synapse'. He proposed that as a result of learning, excitatory synapses show permanently increased excitability. A much broader aspect of this concept was brought up by Edelman [13]. The efficiency of an individual synapse is 'use-dependent' and depends on pre- and postsynaptic excitation. This point of view, known as 'Neuronal Darwinism', based on use-dependent neuronal selection, is an important theory which might account for changes seen during both development and aging and which may also explain the neuronal basis for plasticity in the central nervous system. Indeed, Oppenheim and many other developmental neurobiologists agree that this principle may explain natural cell death during development $[10,38]$. Individual neurons compete for a given target (synapse); those synapses that are activated survive and those that are not used are eliminated $[13,51,66]$.

In this brief review we first present some physiological and morphological changes that selectively occur during aging and in Alzheimer's disease. We propose that differential levels of neuronal atrophy in Alzheimer patients may also be related to 'use-dependency'. Furthermore, we propose that a certain amount of plasticity is preserved during aging and Alzheimer's disease, which is 'use-dependent' and paraphrased by us as "use it or lose it" [55].

\section{Physiological/morphological changes in aging and Alzheimer's disease}

Human and animal studies have demonstrated changes in sleep-wake patterns during aging and in Alzheimer's disease. These include (1) reduced amount of time spent in slow wave sleep (SWS) and rapid eye movement sleep (REM); (2) shortened sleep cycle length with significantly more short awakening; (3) impaired circadian or diurnal rhythms and also a tendency towards poor tolerance in rotating shift-work $[1,2,6,11,34,39,49]$. In our own studies it was found that healthy elderly controls do not show these changes, but Alzheimer patients do (Fig. 1; see also [73]). It seems that both homeostasis and circadian aspects of sleep-wake, body temperature, cortisol rhythms are
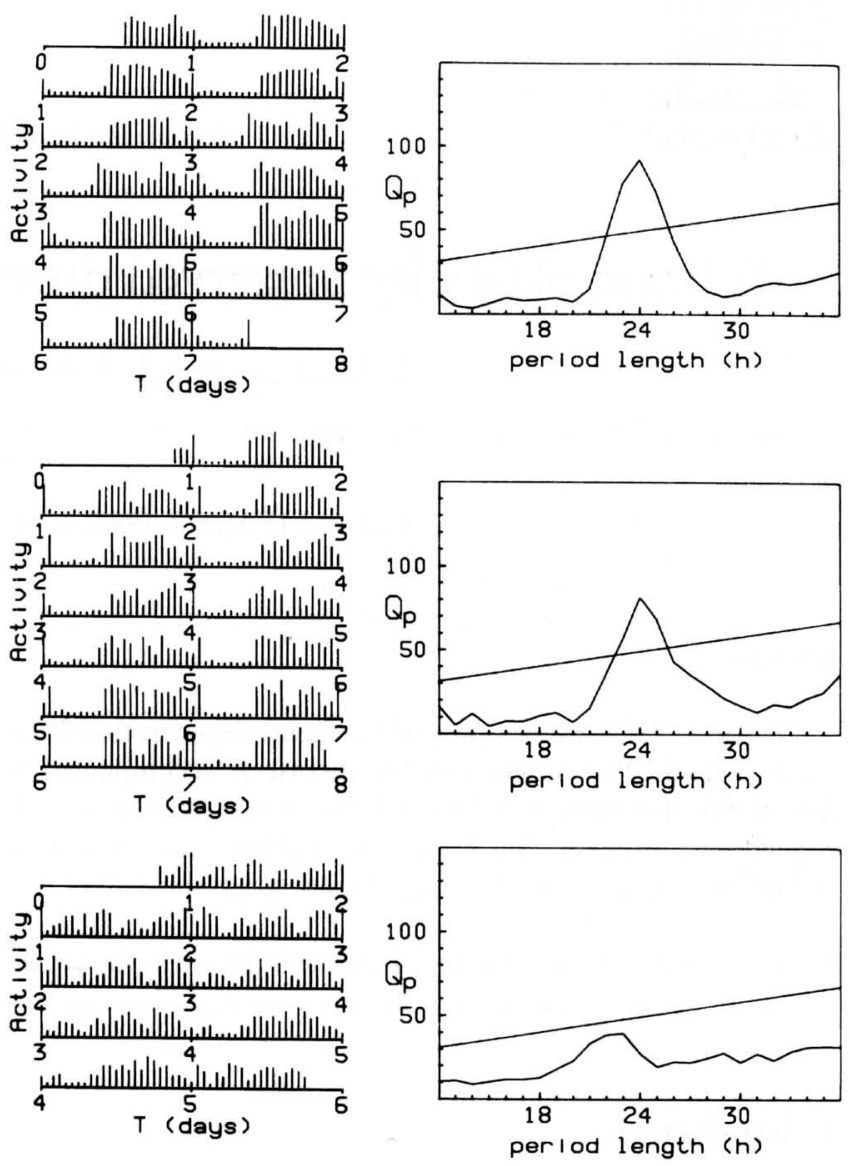

Fig. 1. Rest-activity recorded in middle-aged healthy employed (top) and aged healthy retired (middle) controls and in one Alzheimer patient. The data are double-plotted on successive days of continuous recordings for visualization of the circadian rhythm. On the right side of the periodogram analysis of each subject shows the maximum periodicity of $24 \mathrm{~h}$. The rhythm of the Alzheimer patient is shorter and not statistically significant (the continuous line is the level of significance; for further details see [32]).

influenced during aging and in Alzheimer's disease $[33,52,60,61,64,73]$. A reduction of activity of the suprachiasmatic nucleus ( $\mathrm{SCN}$ ), the biological clock of the brain, may underlie the reduction of circadian rhythm period length, reduced stability and increased variability of these rhythms $[33,35,75]$. Experimentally induced $\beta$-amyloid overexpression in the SCN produces circadian rhythm disturbances in young rats to the same extent as seen in old animals [58]. There is also a clear relationship between the loss of melatonin receptor in the SCN and the degree of circadian rhythm disturbances during aging [71]. Interesting in this respect is that in the human SCN the number of vasopressin-expressing neurons decreases only after the age of 80 and the circadian fluctuations in vasopressin neurons disrupt by the age of 50 [20,21,54]. A more profound change was shown in Alzheimer's disease, which is in support of our findings of more disturbed circadian rhythms in Alzheimer patients than in healthy elderly people [35]. 
Taken together these results are a good example of specific functional/structural changes, namely disturbances of sleep and circadian rhythms with malfunctioning of the biological clock in Alzheimer's disease.

Certain types of learning and memory are impaired in aging and dementia. Olton and Samuelson developed an animal experimental task which is suitable for testing working memory. This spatial task is carried out in a radial maze in which eight or more arms radiate from a central platform. The rat is confined to the center with the doors of the arms closed, while one food pellet is placed at the end of each arm. The optimal strategy for the animal is to obtain pellets from each arm by visiting it once. This task does not require specific or high motor activity and it is especially aimed at memory for recent events. It is therefore very suitable for memory testing in old animals. In our studies we found that old rats made significantly more errors in this task than the young ones. Analysis of the type of errors revealed that old rats were more likely than young ones to repeat the choice for an arm they had just visited [62].

Memory dysfunction is one of the hallmarks of Alzheimer's disease $[28,50,65]$. The current approach in memory research is aimed at how information is processed and used. In general, demented patients are inferior to age-matched controls in several aspects of memory, especially those relating to the acquisition of new information. Word-listing and picture recall are among the tests commonly used in demented subjects, although not all studies take the level of depression, education, language problems, cooperation and stress of these patients into account.

Neuropathological changes during aging and in Alzheimer's disease are reviewed in this volume by Terry (see also [29,59]). One of the main findings is that brain size diminishes during aging and in particular in Alzheimer's disease. This is mainly due to cortical and hippocampal atrophy. It should be noted that cell death is only present in a very limited number of brain areas in Alzheimer patients, e.g., in the locus coeruleus [23], the CA1 of the hippocampus and the temporal cortical area [70], but not as a global phenomenon in the cortex [41]. Indeed, not all areas in the brain are equally affected. For instance, although in the human hypothalamus the SCN shows an age-related decline, particularly in Alzheimer's disease [54], paraventricular neurons of the hypothalamus (in the same group of patients) do not show degenerative changes $([16,27]$, see also [44]). Even within the same brain region there is a differential effect. A sex-dependent effect of Alzheimer's disease was found for VIP neurons of the suprachiasmatic nucleus [77]. In the PVN the number of vasopressin-expressing neurons increases during aging and remains stable in Alzheimer's disease [14,22] and the number of corticotrophin releasing hormone (CRH)-expressing neurons in the PVN increases in aging and Alzheimer's disease
[40]. Recent research favors the idea that even in brain areas such as the nucleus basalis of Meynert neuronal atrophy and decreased neuronal activity (rather than cell death) are the main phenomena in Alzheimer's disease [43]. This means that the key question in Alzheimer's disease is not "how can we prevent cell loss?", but rather "how can we reactivate atrophic neurons?" [56]. Neuronal plasticity could play a central role in this question. As has been mentioned, environmental stimulation can induce an increase in cortical thickness, neuronal branching and number of synapses. If this neuronal plasticity is preserved to some extent in elderly people and Alzheimer patients, environmental stimulation may reactivate atrophic neurons.

\section{Brain plasticity during aging and in Alzheimer's disease}

The level of illumination and the amount of activity both influence circadian rhythms (for review see [61]). We have been able to show by increasing the level of illumination that the amplitude of circadian rhythms increases significantly to the same extent in old as well as young rats [74]. However, it should be noted that this effect was present as long as the environmental stimulation persisted. On the other hand, although increasing activity influences circadian rhythms in young rats, it does not seem to influence old rats at all [67]. It seems as if different populations of neurons in the biological clock responsive to light or activity feedback are lost differentially or their level of responsiveness is differentially reduced.

The level of environmental illumination seems to be very important for the organization of the human circadian timing system too. Campbell et al. have already shown that Alzheimer patients are exposed to a significantly lower amount of light in the environment compared with normal elderly people [8]. Based on these findings we designed an experiment to evaluate the effect of increased environmental illumination in Alzheimer patients in a repeated measurement design (Van Someren et al., submitted; see also [68]). A significant improvement of circadian rhythms by light could be demonstrated following 2 weeks of daily increased illumination. After discontinuation of the bright light treatment rhythm disturbances returned to the pretreatment level (see example in Fig. 2). Thus, although the mechanism regulating circadian rhythms is plastic enough to respond to increased input, no long-lasting changes were induced. Furthermore, it remains to be investigated whether the functional response is paralleled by anatomical changes.

We used the environmental enrichment paradigm (see for details Rosenzweig, this volume) to test the hypothesis that a certain amount of plasticity remains during 


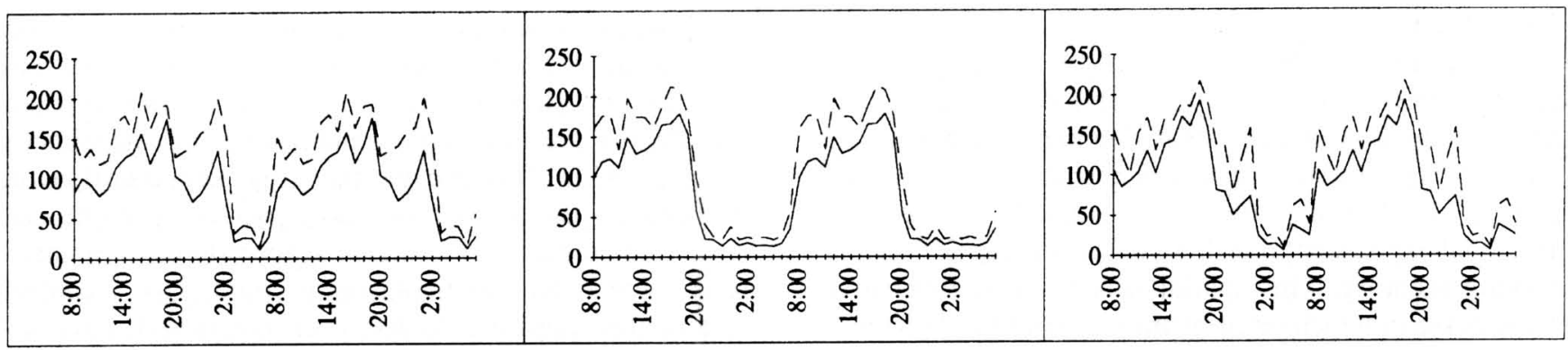

Fig. 2. Double-plot $(2 \times 24$-h) of the average (1-week) activity profile of an Alzheimer patient before (left), during (middle) and after (right) wholeday 2-week bright-light treatment. Solid lines indicate the average activity level, dotted lines indicate one standard deviation above average. Vertical axis represents activity counts per hour. Note the decreased intradaily variability of the rhythm, i.e., a higher signal to noise ratio during the light therapy.

aging. Young and old rats were reared for 2 months in either standard or enriched environments. Although old rats have a significantly smaller cerebral cortex compared with young ones, we found significant effects of environment on cerebral cortical thickness in both young and old rats [31]. The amount and duration of sleep episodes increased as well in both age groups [63]. On the other hand, no significant influence of the environmental enrichment was found in radial maze learning, the recovery cycle of visually evoked potential or the circadian rhythms of sleep-wakefulness $[62,63]$. Other investigators have also shown preservation of certain levels of plasticity during aging. For example, auditory stimulation can enhance rapid eye movement sleep in young as well as old rats [3]. It seems that the recovery of function following brain lesioning is also preserved to some extent in old rats (for review see $[4,5,26,31,69]$ ). Coleman already showed increased dendritic branching in the remaining cortical neurons in Alzheimer's disease [9], interpreted as an indication of increased sprouting following lesioning.

It is essential to study ways in which memory disturbances in Alzheimer's disease can be overcome (see also [30]). For instance, animal studies have shown that transplanting cholinergic neurons into the hippocampal formation can improve memory performance in aged rats in mazes [15]. Whether daily training at early stages of Alzheimer's disease influences the development of memory impairment in these patients is yet to be studied systematically. Behavioral rehabilitation seems to be controversial [31]. On the other hand, as Terry emphasized [59], Alzheimer's disease might occur similarly in patients with varying levels of education (but see also discussion [31]). However, more recent data show a clear negative correlation between the level of education and the probability or developing Alzheimer's disease $[12,37,47,76]$. These postmortem observations suggest indirectly the real possibility of protecting neurons against degenerating by activation. Whether after the onset of Alzheimer, brain activation might prevent its further functional decline and neuronal atrophy is a line of research worth pursuing.
Several lines of evidence are summarized in the paper by Swaab [55] in support of the hypothesis that activation of neurons may promote functional cell survival or even prevent cell death. It is remarkable that despite the widespread neuronal atrophy/cell loss seen in aging and Alzheimer's disease, the neurosecretory neurons of the supraoptic and paraventricular nucleus remain completely intact. These neurons are not only metabolically highly active throughout life, but they are even extraactivated in senescence. Another example of neuronal activation in the physiological range preventing cell loss is shown by ovariectomy, in which LHRH neurons are activated and the loss of LHRH fibers in the arcuate nucleus normally seen in rats during aging is prevented [46].

Animal studies suggest that there are, e.g., differential levels of hypothalamo-hypophysial-adrenal activity in cognitively impaired vs. unimpaired rats [25]. Moreover, there is a clear relationship between sleep and memory disturbances in intact old and amnesic young rats [53]. The specific loss of neuronal firing in those hippocampal cells that are selectively active during the performance of a spatial learning task in old rats is also in support of selective functional impairment rather than a global deterioration in aging. Activation of brain cells could protect them against atrophy and reactivate those cells that have already begun to die. Whether there are differences among neurons with respect to, e.g., DNA damage or indeed the amount of endogenous/exogenous activity of the neuron, or both, that determine the level of neuronal survival and plasticity remains to be studied. The data briefly reviewed here are in support of the hypothesis that at least a certain amount of neuronal survival and plasticity in aging and Alzheimer's disease remains present and is 'use-dependent'.

\section{Acknowledgement}

The secretarial assistance of Miss Olga Pach is gratefully acknowledged. The work of the authors presented 
in this review was partially supported by Senter, The Hague, The Netherlands (project MTR 89026).

\section{References}

[1] Ancoli-Israel, S., Klauber, M.R., Gillin, J.C., Campbell, S.S. and Hofstetter, C.R., Sleep in non-institutionalized Alzheimer's disease patients. Aging Clin. Exp. Res., 6 (1994) in press.

[2] Ancoli-Israel, S. and Kripke, D.F., Now I lay me down to sleep: the problem of sleep fragmentation in elderly and demented residents of nursing homes. Bull. Clin. Neurosci., 54 (1989) 127-132.

[3] Arankowsky-Sandoval, G., Stone, W.S. and Gold, P.E., Enhancement of REM sleep with auditory stimulation in young and old rats. Brain Res., 589 (1992) 353-357.

[4] Arendash, G.W., Millard, W.J., Dunn, A.J. and Meijer, E.M., Long-term neuropathological and neurochemical effects of nucleus basalis lesions in the rat. Science, 238 (1987) 952-956.

[5] Barnes, C.A., McNaughton, B.L. and O'Keefe, J., Loss of place specificity in hippocampal complex spike cells of senescent rat. Neurobiol. Aging, 4 (1983) 113-119.

[6] Biliwise, D.L., Sleep in normal aging and dementia. Sleep, 16 (1993) 40-81.

[7] Blakemore, C. and Cooper, G.F., Development of brain depends on the visual environment. Nature, 228 (1970) 477-478.

[8] Campbell, S.S., Kripke, D.F., Gillin, J.C. and Hrubovac, J.C., Exposure to light in healthy elderly subjects and Alzheimer's patients. Physiol. Behav., 42 (1988) 141-144.

[9] Coleman, P.D. and Flood, D.G., Dendritic proliferation in the aging brain as a compensatory repair mechanism. Prog. Brain Res., 70 (1986) 227-237.

[10] Corner, M.A., Reciprocity of structure-function relations in developing neural networks. Prog. Brain Res., 102 (1994) 3-31.

[11] Czeisler, C.A., Dumont, M., Duffy, J.F., Steinberg, J.D., Richardson, G., Brown, E.N., Sanchez, R., Rios, C.D. and Ronda, J.M., Association of sleep-wake habits in older people with changes in output of circadian pacemaker. Lancet, 340 (1992) 933-936.

[12] Dartigues, J.F., Gagnon, M., Michel, P., Letteneur, I., Commences, D., Barberger-Gateau, P., Auriacombe, S., Rigal, B., Bedry, R., Alperovitch, A., Orgogozo, J.M., Henry, P., Loiseau, P. and Salomon, R., Le programme de recherche paquid sur l'epidemilogie de la Demence; methodes et resultats initiaux. Rev. Neurol., 147 (1991) 225-230.

[13] Edelman, G.M., Neural Darwinism-The Theory of Neural Group Selection. Basic Books, New York, 1987.

[14] Fliers, E., Swaab, D.F., Pool, C.W. and Verwer, R.W.H., The vasopressin and oxytocin neurons in the human supraoptic and paraventricular nucleus, changes with aging and in senile dementia. Brain Res., 342 (1985) 45-53.

[15] Gage, F.H. and Björklund, A., Cholinergic septal grafts into the hippocampal formation improve spatial learning and memory in aged rats by an atropin-sensitive mechanism. J. Neurosci., 6(1986) $2837-2847$.

[16] Goudsmit, E., Hofman, M.A., Fliers, E. and Swaab, D.F., The supraoptic and paraventricular nuclei of the human hypothalamus in relation to sex, age and Alzheimer's disease. Neurobiol. Aging, 11 (1990) 529-536.

[17] Greenough, W.T., Hwang, H.M.F. and Gorman, C., Evidence for active synapse formation of altered postsynaptic mechanism in visual cortex of rat reared in complex environment. Proc. Natl. Acad. Sci. USA, 82 (1985) 4549-4552.

[18] Hebb, O., The Organization of Behavior. Wiley, New York, 1949.

[19] Held, R., Plasticity in sensory motor systems. Sci. Am., 213 (1965) 84-94.

[20] Hofman, M.A., Fliers, E., Goudsmit, E. and Swaab, D.F., Mor- phometric analysis of the suprachiasmatic and paraventricular nuclei in the human: sex differences and age-dependent changes. J. Anat., 160 (1988) 127-143.

[21] Hofman, M.A. and Swaab, D.F., Diurnal and seasonal rhythms of neuronal activity in the suprachiasmatic nucleus of humans. J. Biol. Rhythms, 8 (1993) 283-295.

[22] Hoogendijk, J.E., Fliers, E., Swaab, D.F. and Verwer, R.W.H., Activation of vasopressin neurons in the human supraoptic and paraventricular nucleus in senescence and senile dementia. J. Neurol., Sci., 69 (1985) 291-294.

[23] Hoogendijk, W.J.G., Pool, C.W., Troost, D., Van Zwieten, E. and Swaab, D.F., Image analyser-assisted morphometry of the locus coeruleus in Alzheimer's disease, Parkinson's disease and amyotrophic lateral sclerosis. Brain (1995) in press.

[24] Hubel, D.H., Wiesel, T.N. and Le Vay, S., Functional architecture of area 17 in normal and monocularly deprived macaque monkeys. Cold Spring Harbour Symp. Quant. Biol., 40 (1976) 381-389.

[25] Issa, A.M., Rowe, W., Gauthier, S. and Meaney, M.J., Hypothalamic-pituitary-adrenal activity in aged, cognitively impaired and cognitively unimpaired rats. J. Neurosci., 10 (1990) 3247-3254.

[26] Kuchel, G.A. and Zigmond, R.E., Functional recovery and collateral neuronal sprouting examined in young and aged rats following a partial neural lesion. Brain Res., 540 (1991) 195-203.

[27] Lucassen, P.J., Salehi, A., Pool, C.W., Gonatas, N.K. and Swaab, D.F., Activation of vasopressin neurons in aging and Alzheimer's disease. J. Neuroendocrinol., 6 (1994) 673-679.

[28] McKhann, G., Drachman, D. and Fallstein, M., Clinical diagnosis of Alzheimer's disease; Report of the NINCDS-ADRDA workgroup under the auspices of the Dept. Health Human Services Task Force on Alzheimer's disease. Neurobiology, 34 (1984) 939-944

[29] Mesulam, M.M. and Geula, C., Acetylcholinesterase-rich pyramidal neurons in the human neocortex and hippocampus: absence at birth, development during the life span and dissolution in Alzheimer's disease. Am. Neurol., 24 (1988) 765-773.

[30] Millard, P.H., Treatment for aging brains. Br. Med. J., 289 (1984) 1094.

[31] Mirmiran, M., Van Gool, W.A., Van Haaren, F. and Polak, C.E., Environmental influences on brain and behavior in aging and Alzheimer's disease. Prog. Brain Res., 70 (1986) 443-459.

[32] Mirmiran, M., Overdijk, J., Witting, W., Klop, A. and Swaab, D.F. A method for recording and analysing circadian rhythms in man. J. Neurosci. Methods, 25 (1988) 209-214.

[33] Mirmiran, M., Swaab, D.F., Witting, W., Honnebier, M.B.O.M., Van Gool, W.A. and Eikelenboom, P., Biological clocks in development, aging and Alzheimer's disease. Brain Dysfunct., 2 (1989) 57-66.

[34] Mirmiran, M., Witting, W., Swaab, D.F., Eikelenboom, P. and Van Gool, W.A., Sleep and circadian rhythm changes in Alzheimer's disease. In S. Smirne, M. Franchechi and L. Ferini Strambi (Eds.) Sleep and Aging, Masson, Milan, 1991, pp. 57-64.

[35] Mirmiran, M., Swaab, D.F., Kok, J.H., Hofman, M.A., Witting, W. and Van Gool, W.A. Circadian rhythms and the suprachiasmatic nucleus in perinatal development, aging and Alzheimer's disease. Prog. Brain Res., 93 (1992) 151-163.

[36] Omitted.

[37] Mortimer, J.A. and Graves, A.B., Education and other socioeconomic determinants of dementia and Alzheimer's disease. Neurology, 43 (Suppl. 4) (1993) S39-S44.

[38] Oppenheim, R.W., The neuroembryological study of behavior: progress, problems and perspectives. Curr. Topics Dev. Biol., 17 (1982) 257-309.

[39] Prinz, P.N., Poceta, J.S. and Vitiello, M.V., Sleep in the dementing disorders. In F. Boller and J. Grafman (Eds.) Handbook of Neuropsychology, Vol. 4, Elsevier, Amsterdam, 1990, pp. 335-347.

[40] Raadsheer, F.C., Van Heerikhuize, J., Lucassen, P.J., Tilders, F.J.H. and Swaab, D.F., Increased corticotropin releasing hor- 
mone (CRH) mRNA in the paraventricular nucleus of patients with Alzheimer's disease or depression. Submitted.

[41] Regeur, L., Badsberg Jensen, G., Pakkenberg, H., Evans, S.M. and Pakkenberg, B., No global neocortical nerve cell loss in brains from patients with senile dementia of Alzheimer's type. Neurobiol. Aging, 15 (1994) 347-352.

[42] Omitted.

[43] Salehi, A., Lucassen, P., Pool, C.W., Gonatas, N.K., Ravid, R. and Swaab, D.F., Decreased neuronal activity in the nucleus basalis of Meynert in Alzheimer's disease as suggested by the size of the Golgi apparatus. Neuroscience, 59 (1994) 871-880.

[44] Saper, C.B. and German, D.C., Hypothalamic pathology in Alzheimer's disease. Neurosci. Lett., 74 (1987) 364-370.

[45] Omitted.

[46] Schipper, H., Brawer, J.R., Nelson, J.F., Felicio, L.S. and Finch, C.E., Role of the gonads in the histologic aging of the hypothalamic arcuate nucleus. Biol. Reprod., 25 (1981) 413-419.

[47] Schofield, P.W., Mosesson, R.E., Stern, Y. and Mayeux, R., The age of onset of Alzheimer's disease and an intracranial area measurement. Arch. Neurol., 52 (1995) 95-98.

[48] Shatz, C.J. and Stryker, M.P., Prenatal tetrodotoxine infusion blocks segregation of retinogeniculate afferents. Science, 242 (1988) 87-89.

[49] Shibata, S., Minamoto, Y., Ono, M. and Watanabe, S., Agerelated impairment of food anticipatory locomotor activity in rats. Physiol. Behav., 55 (1994) 875-878.

[50] Shuttleworth, E.C. and Huber, S.J. The naming disorder of dementia of Alzheimer's type. Brain Language, 34 (1988) 222-234.

[51] Siegel, M., Marder, E. and Abbott, L.F., Activity-dependent current distribution in model neurons. Proc. Natl. Acad. Sci. USA, 91 (1994) 11308-11312.

[52] Skene, D.J., Vivien-Roels, B., Sparks, D.L., Hunsaker, J.C., Pévet, P., Ravid, R. and Swaab, D.F., Daily variation in the concentration of melatonin and 5-methoxytryptophol in the human pineal gland: effect of age and Alzheimer's disease. Brain Res., 528 (1990) 170-174.

[53] Stone, W.S. and Gold, P.E., Sleep and memory relationships in intact old and amnesic young rats. Neurobiol. Aging, 9 (1988) 719-727.

[54] Swaab, D.F., Fliers, E. and Partiman, T.S., The suprachiasmatic nucleus of the human brain in relation to sex, age and senile dementia. Brain Res., 342 (1985) 37-44.

[55] Swaab, D.F., Brain aging and Alzheimer's disease, wear and tear versus use it or lose it. Neurobiol. Aging, 12 (1991) 317-324.

[56] Swaab, D.F., Hofman, M.A., Lucassen, P.J., Salehi, A. and Uylings, H.B.M., Neural atrophy, not cell death is the main hallmark of Alzheimer's disease. Neurobiol. Aging, 3 (1994) 369-371.

[57] Swanson, L.W., Teijler, T.J. and Thompson, R.F., Hippocampal long-term potentiation: mechanisms and implications for memory. Neurosci. Res. Progr. Bull., 20 (1982) 613-769.

[58] Tate, B., Aboody-Guterman, K.S., Morris, A.M., Walcott, E.C., Majocha, R.E. and Marotta, C.A., Disruption of circadian regulation by brain grafts that overexpress Alzheimer's $\beta / \mathrm{A} 4$ amyloid. Proc. Natl. Acad. Sci. USA, 89 (1992) 7090-7094.
[59] Terry, R.D., Interrelations among the lesion of normal and abnormal aging of the brain. Prog. Brain Res., 70 (1986) 41-48.

[60] Touitou, Y., Effects of aging on endocrine and neuroendocrine rhythms in humans. Hormone Res., 43 (1995) 12-19.

[61] Turek, F.W. Circadian rhythms. Recent Prog. Hormone Res., 49 (1994) 43-90.

[62] Van Gool, W.A., Mirmiran, M. and Van Haaren, F., Spatial memory and visual evoked potentials in young and old rats after housing in an enriched environment. Behav. Neural Biol., 44 (1985) 454-469.

[63] Van Gool, W.A. and Mirmiran, M. Effects of aging and housing in an enriched environment on sleep-wake patterns in rats. Sleep, 9 (1986) 333-347.

[64] Van Gool, W.A. and Mirmiran, M., Aging and circadian rhythms. Prog. Brain Res., 70 (1986) 255-277.

[65] Van Gool, W.A. and Bolhuis, P.A., Cerebrospinal fluid markers of Alzheimer's disease. JAGS, 39 (1991) 1025-1039.

[66] Van Ooyen, A., Van Pelt, J. and Corner, M.A., Implications of activity-dependent neurite outgrowth for neuronal morphology and network development. J. Theor. Biol., 172 (1995) 63-82.

[67] Van Reeth, O., Zhang, Y., Reddy, A., Zee, P. and Turek, F.W., Aging alters the entraining effects of an activity-inducing stimulus on the circadian clock. Brain Res., 607 (1993) 286-292.

[68] Van Someren, E.J.W., Mirmiran, M. and Swaab, D.F., Non-pharmacological treatment of sleep and wake disturbances in aging and Alzheimer's disease: chronobiological perspectives. Behav. Brain Res., 57 (1993) 235-253.

[69] Wellman, C.L. and Sengelaub, D.R., Alterations in dendritic morphology of frontal cortical neurons after basal forebrain lesions in adult and aged rats. Brain Res., 669 (1995) 48-58.

[70] West, M.J., Coleman, P.D., Flood, D.G. and Troncoso, J.C., Differences in the pattern of hippocampal neuronal loss in normal ageing and Alzheimer's disease. Lancet, 344 (1994) 769-772.

[71] Whealin, J.M., Burwell, R.D. and Gallagher, M., The effects of aging on diurnal water intake and melatonin binding in the suprachiasmatic nucleus. Neurosci. Lett., 154 (1993) 149-152.

[72] Omitted.

[73] Witting, W., Kwa, I.H., Eikelenboom, P., Mirmiran, M. and Swaab, D.F., Alterations in the circadian rest-activity rhythm in aging and Alzheimer's disease. Biol. Psychiatry, 27 (1990) 563-573.

[74] Witting, W., Mirmiran, M., Bos, N.P.A. and Swaab, D.F., Effect of light intensity on diurnal sleep-wake distribution in young and old rats. Brain Res. Bull., 30 (1993) 157-162.

[75] Witting, W., Mirmiran, M., Bos, N.P.A. and Swaab, D.F., The effect of old age on the free-running period of circadian rhythms in rat. Chronobiol. Int., 11 (1994) 103-112.

[76] Zhang, M., Katzman, R., Salmon, D., Jin, H., Cai, G., Wang, Z., Qu, G., Grant, I., Yu, E., Levy, P., Klauber, M.R. and Liu, W.T., The prevalence of dementia and Alzheimer's disease in Shanghai, China: impact of age, gender and education. Ann. Neurol., 27 (1990) 428-437.

[77] Zhou, J.N., Hofman, M.A. and Swaab, D.F., Vasoactive intestinal polypeptide (VIP) neurons in the human suprachiasmatic nucleus (SCN) in relation to sex, age and Alzheimer's disease. Neurobiol. Aging (1995) in press. 